AUTHORS:

Moses Zimba

Clemence Zimudzi ${ }^{1}$

\section{AFFILIATION:}

'Department of Biological

Science, University of

Zimbabwe, Harare, Zimbabwe

\section{CORRESPONDENCE TO:}

Moses Zimba

EMAIL:

mzimba@science.uz.ac.zw

\section{DATES:}

Received: 11 Dec. 2015

Revised: 23 Feb. 2016

Accepted: 19 Apr. 2016

\section{KEYWORDS:}

organophosphates; pyrethroids; poisoning; counterfeit; agrochemicals

\section{HOW TO CITE:}

Zimba M, Zimudzi C. Pesticide management practices among rural market gardening farmers near Harare, Zimbabwe.

S Afr J Sci. 2016;112(9/10), Art. \#2015-0443, 5 pages. http://dx.doi.org/10.17159/ sajs.2016/20150443

\section{ARTICLE INCLUDES: \\ $\times$ Supplementary material \\ $\times$ Data set}

FUNDING:

None

(c) 2016. The Author(s).

Published under a Creative Commons Attribution Licence.

\title{
Pesticide management practices among rural market gardening farmers near Harare, Zimbabwe
}

\begin{abstract}
In 2014, we carried out a survey in Chinamhora and Chihota communal lands on the outskirts of Harare city, with the aim of understanding pesticide management practices among market gardening farmers. The farmers grew vegetables that mostly included tomatoes, cabbages, rape, cucumbers, onions and carrots, and they used mainly organophosphates and pyrethroids to control pests. A questionnaire was administered to 119 male heads of households across both study areas. The questionnaire contained 13 closed-ended questions in three sections: source and quality of pesticides, handling and use, and storage and disposal of pesticides used to protect crops. The study identified numerous gaps related to the handling of pesticides. Although the quality of labelling and packaging can largely identify the quality of pesticide, most of the farmers (77.3\%) could not distinguish between genuine and counterfeit pesticides; approximately half $(47.9 \%)$ of the farmers were not concerned about expiry dates; $27 \%$ did not observe post-spray periods; and $63 \%$ did not take precautions according to colour-coding of the pesticides. Also of concern were the large numbers of farmers who were not using protective coveralls (54.3\%); a substantial number who were not using knapsacks for spraying (21.8\%); poor storage of the pesticides, as shown by the variation in storage facilities; the use of empty pesticide containers for domestic purposes (20.2\%); and lack of strict adherence to recommended dose levels, with some farmers $(28.6 \%)$ merely estimating the dilution of pesticides. Training through outreach programmes is recommended.

\section{Significance:}

- Identifies gaps in the way pesticides are used and stored by rural market gardening farmers.

- Highlights the need for government agricultural extension workers to hold regular workshops for farmers.

- Indicates the need for government ministries to monitor counterfeit pesticides.
\end{abstract}

\section{Introduction}

Market gardening of vegetables in Zimbabwe involves intensive use of pesticides to maximise yields. Pesticides are inherently toxic materials, and have been an essential component of insect pest control since the early 1950s when organochlorine insecticides were first widely introduced. ${ }^{1}$ Official records of the quantity of insecticides used in Zimbabwe annually are not available, but the amounts must be huge because the country has an agrobased economy. According to the World Health Organization $\left(\mathrm{WHO}^{2}\right)$, the level of safe pesticide management in developing countries is low. When improperly used, pesticides can have effects such as poisoning through direct ingestion or accumulation in food, and may lead to insecticide resistance in target pests. ${ }^{3}$

The $\mathrm{WHO}^{2}$ has defined pesticide management as the regulatory control, proper handling, import, supply, transport, storage, use and disposal of pesticide waste to minimise adverse environmental effects and human exposure. In Zimbabwe, it is a statutory requirement for pesticide containers to be marked with a triangle that is green, amber, red or purple based on the toxicity of the pesticide. ${ }^{4}$ Green means formulations that have an acute oral dosage (LD50) of over $2001 \mathrm{mg} / \mathrm{kg}$ of bodyweight. These pesticides can be used without danger in the home, or where stated, as admixture to grain or other stored produce for human or animal consumption. They can be sold by any shop or store. The word 'Caution' is written in a green triangle, and 'Harmful if swallowed' appears at the base of the triangle. ${ }^{4}$ An amber triangle means a formulation having an LD50 of between 501 and 2000, which can be used without danger in home gardens and for external use about the home. The word 'Danger' appears with a symbol of skull-and-crossbones within the amber triangle, and the word 'Poison' is written at the triangle base. ${ }^{4}$

Red formulations have an LD50 of between 100 and 500 . Their use should generally be restricted to horticultural, agricultural, health or industrial pest control operations. They may be sold by a licensed dealer if part of the premises is set aside for the storage and sale of dangerous substances. The word 'Danger' with a skull-andcrossbones symbol appears within the red triangle, with the words 'Dangerous poison' beneath the base of the triangle. ${ }^{4}$ Purple triangles mean a formulation with an LD50 of up to 1000 . These pesticides may be sold only to persons whose business, profession or trade requires them. They may only be offered for sale by licensed dealers where part of the premises is set aside for the sale of dangerous substances. The dealer must keep a person register of all sales of this group of pesticide, each sale being countersigned by the purchaser or his nominee and the firm's license number noted. The word 'Danger' with a skull-and-crossbones symbol appears within the purple triangle, and 'Very dangerous poison' is written at the triangle base. ${ }^{4}$

In common with other countries, Zimbabwe has statutory instruments under the Environmental Management Act that regulate pesticide use, both in agriculture and for public health. Globally, the public health sector uses large quantities of pesticides. ${ }^{5}$ However, the bulk of pesticides for public health are used indoors, for 
example to control malaria vectors using indoor residual spraying, or to control bedbugs and cockroaches. By contrast, almost all agricultural pesticides are applied in the open environment. Monitoring and enforcement of regulations on the use of pesticides is a major challenge. According to $\mathrm{WHO}^{2}$, poor capacity to enforce regulations leads to the excessive and unsafe use of pesticides, which can result in the contamination of food, drinking water and the environment, as well as affecting aquatic organisms. Globally, use of pesticides in agriculture has been reported to contribute to insecticide resistance in insect vectors of disease. ${ }^{5}$ The availability of substandard, illegal and counterfeit pesticide products on the market is also of great concern. ${ }^{1}$

To promote pesticide management practices that are safe to human health and the environment, an International Code of Conduct on the distribution and use of pesticides was formulated. ${ }^{2} \mathrm{~A}$ study on organophosphate poisoning in Zimbabwe from 1995 to $2000^{6}$ showed that of the 92 children (under 10 years old) who ingested this type of pesticide, $62 \%$ of cases were the result of accidental ingestion. It is important to be able to read and understand the instructions on pesticide containers. Cases of misuse of pesticides resulting in death are common throughout the world. In the U.S., Morgan et al. ${ }^{7}$ reported 135 cases and 8 deaths among people who ate watermelons that had been treated with albicarb, a systemic pesticide not registered for such use. Rowley et al. ${ }^{8}$ reported an outbreak of eldrin poison in Attock district of Pakistan, in which out of 194 people who were poisoned, 19 died. Numerous cases of pesticide poisoning and deaths have also been reported in Zimbabwe. ${ }^{9,10}$

The use of appropriate protective clothing, including face masks, is strongly recommended. Chavez et al. ${ }^{11}$ reported the occurrence of optic nerve atrophy among people who had been exposed to methyl bromide. Proper storage of pesticide is also an important management issue. Cases have been reported of people easily accessing pesticides for purposes of committing suicide, and those who survived suffering from chronic fibrotic changes. ${ }^{12}$ In Zimbabwe, studies on occupational hazards of pesticide use and handling have shown that more than $50 \%$ of farm workers were exposed to organophosphates during spraying. ${ }^{13}$

The demand for market gardening produce to feed a rapidly growing urban population has resulted in intensive farming around urban centres in Zimbabwe. Pesticide management practices in these farming areas are little understood. We aimed to determine pesticide management practices among market gardening communities on the outskirts of Harare, with a view to promoting outreach training programmes. The specific objectives were to identify the pesticides used in market gardening by small-scale market gardening communities on the outskirts of Harare, who supply produce to Harare city; to examine pesticide storage, usage and disposal practices among the communities; and to recommend strategies and action plans to strengthen pesticide management practices among the communities.

\section{Materials and methods}

\section{Study sites}

The study was conducted in Chinamhora $\left(17^{\circ} 06^{\prime} \mathrm{S}, 31^{\circ} 13^{\prime} \mathrm{E}\right)$ and Chihota $\left(18^{\circ} 05^{\prime} \mathrm{S}, 31^{\circ} 06^{\prime} \mathrm{E}\right)$ communal areas, situated approximately $30 \mathrm{~km}$ and $27 \mathrm{~km}$ north and south-east of Harare respectively. In selecting the study sites, consideration was given to similarities in their physical and socio-economic characteristics. Communal farmers in both study areas practised intensive perennial commercial market gardening of vegetables, tomatoes, cucumbers and carrots, along the banks of slow-flowing perennial streams. The farmers also keep cattle and goats. Harare is the major market for their produce, where it is sold wholesale. The farmers we interviewed used agricultural pesticides intensively.
Participants were identified from records of market-gardening farmers kept by Harare Municipality at the Department of Community Services. The two study areas included 142 household, 78 in Chinamhora and 64 in Chihota. Of these households, 62 were sampled from Chinamhora and 57 from Chihota, resulting in a total of 119 sampled households. Most of the farmers had houses with brick walls under tiles or asbestos. All surveyed households had blair toilets. Because of their proximity to Harare, the two study sites have had both primary and secondary schools for decades, and this influenced the literacy rate of inhabitants of the two study sites.

\section{Survey methodology}

A pilot study was conducted in 2014 using a closed-ended questionnaire adopted by WHO in a world survey on pesticide registration and management ${ }^{2}$, with minor modifications. The questionnaire had 13 questions and was administered to 119 male heads of households who were engaged in market gardening. All respondents were interviewed at their homesteads and they provided individual consent to be interviewed. After the interviews, we gave the farmers pamphlets with information on proper procurement, safe use, storage and disposal of pesticide containers.

\section{Analysis of responses}

Data were analysed according to the method used by $\mathrm{WHO}^{2}$, after the responses were captured on a Microsoft Excel spreadsheet. For analysis of responses to a particular question, the denominator was the number of farmers who responded to that question. Frequencies were converted to percentages to show the frequency distribution of response categories. The chi-square $\left(\chi^{2}\right)$ test was used to determine whether the observed differences in percentages among response categories were statistically significant at $p<0.05$.

\section{Results and discussion}

We interviewed 119 farmers, 62 (52.1\%) of whom lived in Chinamhora and $57(47.9 \%)$ of whom lived in Chihota. Pesticides used by the farmers were of two types, according to their formulations, namely emulsifiable concentrates (EC) and wettable powders. The two most commonly used pesticides were organophosphates, which are marked by red triangles, and synthetic pyrethroids, which are marked by green triangles. Organophosphates include lambda-cyhalothrin $(50 \% \mathrm{EC})$ and fenvalerate (20\% EC), and synthetic pyrethroids include malathion ( $50 \% \mathrm{EC})$, diamethoate $(40 \% \mathrm{EC})$ and amitraz (20\% EC). As mentioned earlier, 'red' pesticide formulations should be used only for horticultural, agricultural, health or industrial pest control operations. ${ }^{4}$ 'Green' pesticides can be used without danger in the home or where stated as admixture to grain or other stored produce for human or animal consumption. ${ }^{4}$

Most of the farmers in our study (83 or $69.7 \%$ ) reported that they obtained their market-gardening pesticides from urban retail shops. Slightly more than a tenth of the sample (17 or $14.3 \%$ ) said they obtained pesticides from rural retail shops; a few (8 or 6.7\%) bought pesticides from rural cooperative facilities; and several (11 or $9.2 \%$ ) purchased from other sources, such as other local farmers. The sources of pesticides varied, with a significant difference $\left(\chi^{2}=171.3\right.$, d.f. $=3$, $p<0.00001$ ) between sources in terms of the frequency of household responses to this question. The fact that the majority of farmers said they obtained their pesticides from urban retail shops might indicate that this is a relatively cheap source.

Most of the farmers ( 81 or $68.1 \%$ ) were concerned to a major extent by substandard and/or counterfeit pesticide products. More than a quarter (28 or $23.5 \%$ ) indicated moderate concern, and a few (10 or $8.4 \%$ ) had minor concerns (Figure 1). There was a significant difference $\left(\chi^{2}=103.0\right.$, d.f. $=2, p<0.00001$ ) between response categories for degree of concern about counterfeit pesticides, in terms of household percentages. 


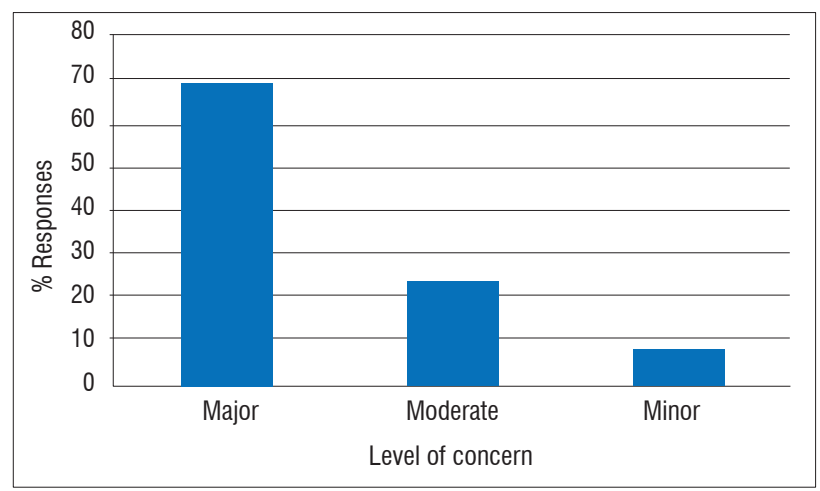

Figure 1: Response categories for concern about substandard or counterfeit pesticides.

Only $27(22.7 \%)$ of the farmers we interviewed stated that they could distinguish between genuine and counterfeit pesticides to a large extent. A slightly bigger group (32 or $26.9 \%$ ) said they could distinguish the difference to some extent, and a smaller group (20 or $16.8 \%$ ) said they could not tell the difference at all. Roughly a third of participants (40 or $33.6 \%$ ) said they could distinguish the difference to a small extent (Figure 2). There was a significant difference $\left(\chi^{2}=9.5\right.$, d.f. $=3$, $p<0.05$ ) between response categories in percentage of household replies to the question about distinguishing between genuine and counterfeit pesticides.

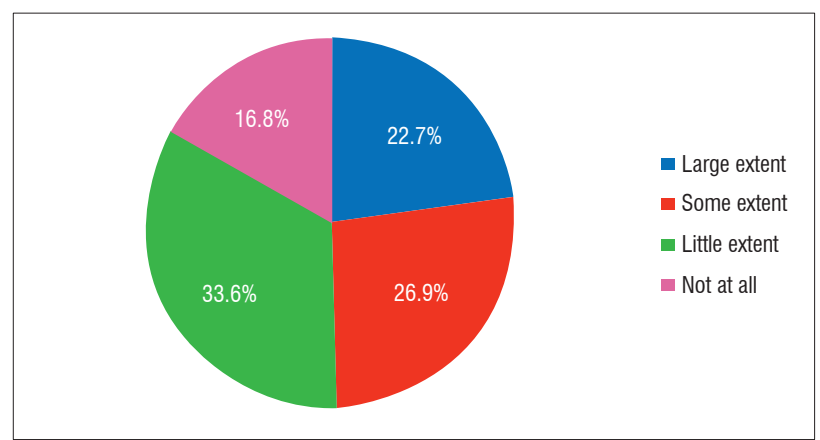

Figure 2: Responses about ability to distinguish genuine from counterfeit pesticides.

Because of the liberalisation of the economy, many unregistered pesticides have appeared on the market in Zimbabwe. A joint study by the Food and Agriculture Organization of the United Nations together with WHO showed that an estimated $30 \%$ of pesticides imported and marketed in developing nations (including in Africa) fall short of internationally accepted quality standards. ${ }^{14}$ Our study showed that the ability of the farmers to distinguish genuine from counterfeit pesticides was poor. The use of substandard and counterfeit pesticide products has serious adverse effects on human health and the environment. ${ }^{2} \mathrm{~A}$ recent survey involving 32 countries in the WHO Afro region showed that many countries were concerned by the trade and use of substandard pesticides. $^{2}$ However, despite these concerns, only $40 \%$ of African countries are reported to have national pesticide quality control facilities. ${ }^{2}$

All 119 respondents in our study reported that they were aware that pesticides have expiry dates. However, when asked whether they adhere to expiry dates, just over half (62 or $52.1 \%$ ) of our respondents stated they always adhere to pesticide expiry dates; a smaller group (44 or $37 \%)$ said they adhere to pesticide expiry dates most of the time, and a tenth (13 or $10.9 \%$ ) said they sometimes adhere to expiry dates (Figure 3). Hence, although a small majority of farmers stated they always adhered pesticide expiry dates, the large number of farmers who might not $(47.9 \%)$ is cause for concern. There was a significant difference $\left(\chi^{2}=46.5\right.$, d.f. $\left.=2, p<0.00001\right)$ between response categories in percentages of household replies to the question on adherence to expiry dates.

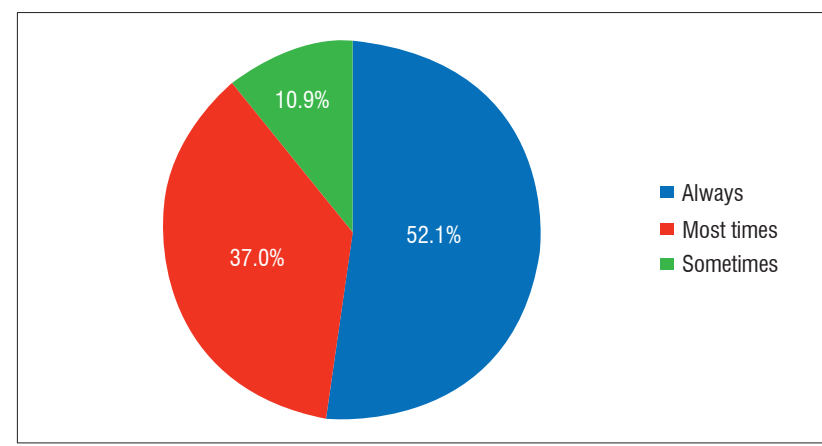

Figure 3: Responses about extent of adherence to pesticide expiry dates.

We also asked the participants about their adherence to a post-spray period before harvest. Overall, $73(61.3 \%)$ of the farmers said they always observed a post-spray period, $30(25.2 \%)$ observed a postspray period most of the time, and $16(13.4 \%)$ sometimes observed the period (Figure 4). Given that only $61 \%$ of the farmers said they always adhered to a post-spray period before harvest, evidently a large number of farmers in the study area were selling produce that still contained pesticides. There was a significant difference $\left(\chi^{2}=66.7\right.$, d.f. $=2$, $p<0.00001$ ) between response categories in percentages of household replies to the question on observation of a post-spray period. Adherence to the recommended period before harvest is critically important to prevent poisoning through ingestion of pesticide residues.

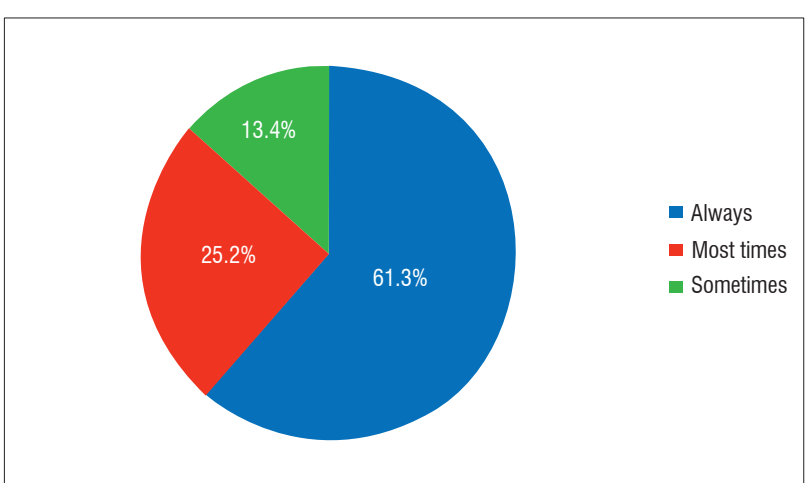

Figure 4: Responses about adherence to the recommended post-spray period.

With regard to colour coding, 44 (37.0\%) of the farmers reported that they always take precautions according to the colour coding of pesticides. Just over a quarter (33 or $27.7 \%$ ) said they do so most of the time, and the same number (33 or $27.7 \%$ ) said they observed colour coding only sometimes; a minority ( 9 or $7.6 \%$ ) said they do not observe colour coding at all (Figure 5). Less than $40 \%$ of respondents indicated that they always read instructions and take precautions according to the colour coding of a pesticide. There was a significant difference $\left(\chi^{2}=29.3\right.$, d.f. $=3, p<0.00001$ ) between response categories in percentages of household replies to the question on precautions and colour coding.

A study among farm workers in Zimbabwe ${ }^{15}$ showed that ignorance of colour codes was a major problem and a risk factor for pesticide exposure. Understanding colour coding on pesticide containers is therefore important to prevent pesticide poisoning. Labels carry colour codes to indicate the toxicity level of particular pesticides, and instructions on use and first aid information. In a similar study conducted among small-scale farmers in Nigeria ${ }^{16}, 88 \%$ of respondents said they did not refer to the material data sheets that accompanied pesticides. Cases of death from pesticide poisoning have been reported worldwide - for example a study by Morgan et al. ${ }^{7}$ reported eight deaths among people who ate watermelons treated with albicarb. A study in Tanzania showed that most small-scale farmers in the study area applied pesticides that lacked specific instructions or labels, and $60 \%$ of respondents reported that they typically fell ill after pesticide application. ${ }^{17}$ 


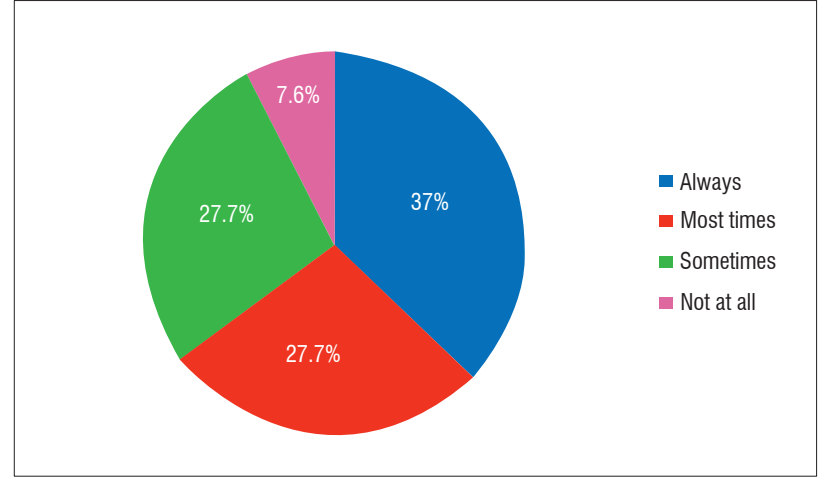

Figure 5: Responses about reading instructions and taking precautions based on colour coding of pesticides.

With regard to method of application, most farmers (93 or 78.2\%) reported that they used knapsack sprayers; a tenth (13 or 10.9\%) were using Hudson pressure pumps, and another tenth (13 or 10.9\%) used traditional brooms. Knapsack sprayers and Hudson pressure pumps are the recommended pesticide application devices in Zimbabwe. Use of an appropriate device minimises exposure to and wastage of pesticides. Our findings showed that farmers in the study area do recognise the benefits of using the recommended equipment.

Fewer than half (52 or 43.7\%) of the respondents said that they use coveralls such as overalls, work suits or dust coats when spraying. More than half (66 or $55.5 \%$ ) stated that they use a respirator or piece of cloth to cover the nose, and more than half $(70$ or $58.8 \%)$ said they wear gumboots (Figure 6). There was a significant difference $\left(\chi^{2}=6.0\right.$, d.f. $=2, p<0.05$ ) between response categories in terms of percentages of household replies to questions about protective clothing. The results showed that slightly more than half of the respondents used a face cover and gumboots, and fewer than half wore overalls, when using pesticides. Magauzi et al. ${ }^{15}$ reported that low provision of protective clothing was a major risk factor for pesticide poisoning among farm workers in Zimbabwe. In many African countries, poor utilisation of protective clothing is a serious problem among small-scale farmers. Olowogbon ${ }^{13}$ reported that $81 \%$ of workers did not use a complete outfit of recommended personal protective equipment while mixing and applying agrochemicals, and $79 \%$ did not calibrate the sprayers before use. These are major gaps in pesticide management, because protective clothing is meant to prevent entry of pesticides into the body.

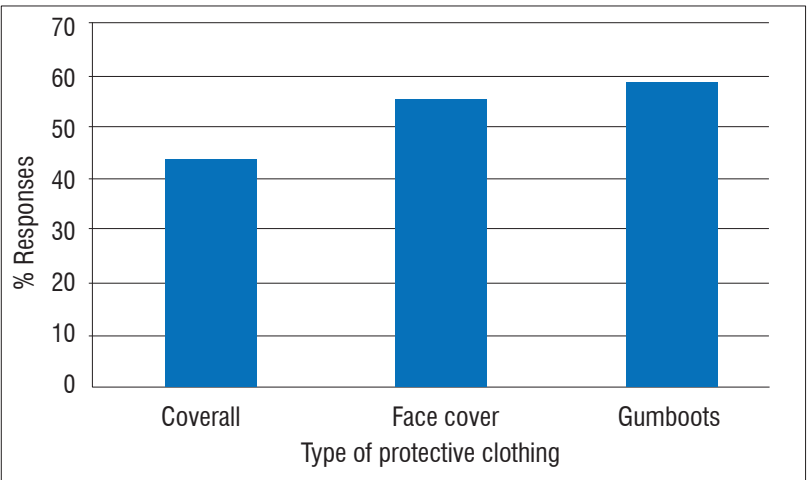

Figure 6: Responses regarding the use of protective clothing.

Only a quarter ( 30 or $25.2 \%$ ) of the farmers reported that they had received formal training in the safe use of pesticides. A fifth of the sample group (24 or $20.2 \%$ ) obtained information from the mass media; more than a third ( 45 or $37.8 \%$ ) got their information from other farmers, and a sixth (20 or 16.8\%) obtained information from the pesticide labels (Figure 7). There was a significant difference $\left(\chi^{2}=16.1\right.$, d.f. $\left.=3, p<0.05\right)$ between response categories in percentages of household replies to the question about training in the safe use of pesticides. The low number of farmers who received training indicates that services by agricultural extension workers were not adequately reaching communal farmers. This finding confirms a WHO (2010) world survey, which highlighted gaps in training on safe use of pesticides both in government and the private sector. ${ }^{2}$ The WHO study ${ }^{2}$ also identified deficiencies in supervision, equipment maintenance, pesticide mixing and calibration in the countries surveyed.

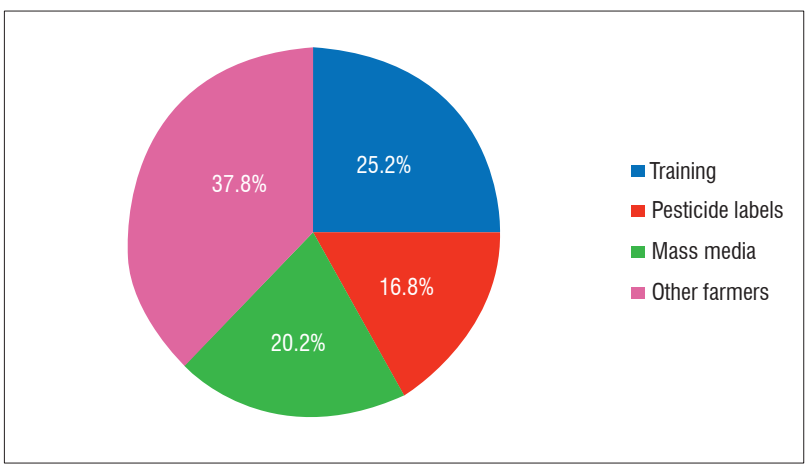

Figure 7: Responses about source of information on safe use of pesticides.

A third of the participants (39 or $32.8 \%$ ) indicated that they used graduated containers to measure liquid pesticides when mixing. More than a third (46 or $38.7 \%$ ) reported that they used containers they had calibrated, and just over a quarter (34 or $28.6 \%$ ) relied on estimation.

With regard to storage, a quarter of the farmers (30 or $25.2 \%$ ) stated that they stored pesticides in secure places in the field; just over a quarter (33 or $27.7 \%$ ) said they kept pesticides in implement storerooms in the home; just over a fifth ( 26 or $21.8 \%$ ) had chemical cabinets in the home; several participants (17 or $14.3 \%$ ) stored pesticides in their granaries; and a few (13 or $10.9 \%)$ stated that they stored pesticides in the eaves of their houses (Figure 8). We statistically examined these variations in methods of pesticide storage. The results showed a significant difference $\left(\chi^{2}=15.3\right.$, d.f. $\left.=4, p<0.05\right)$ between response categories in terms of household replies about the storage of pesticides.

The Food and Agriculture Organization ${ }^{1}$ has highlighted the importance of rules on proper storage of pesticides in order to maintain product efficacy and to prevent contamination of the surroundings. The $\mathrm{WHO}^{2}$ reported that storage of pesticides by small-scale farmers is still a major challenge in many developing countries. Studies on organophosphate poisoning in Zimbabwe from 1995 to $2000^{6}$ showed that among cases of children (up to 10 years old) who ingested this group of pesticides, $62 \%$ cases involved accidental ingestion. ${ }^{6}$

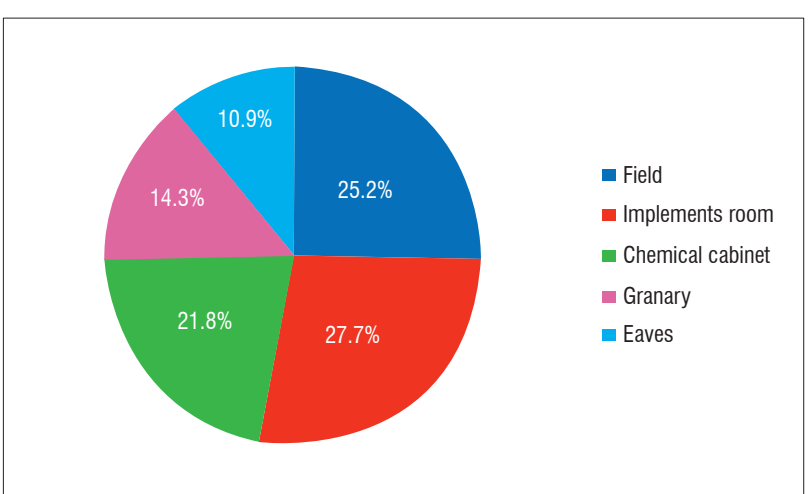

Figure 8: Responses regarding pesticide storage facility.

Almost half ( 55 or $46.2 \%$ ) of the respondents stated that they repeated spraying until all mixed pesticide was finished. Slightly fewer participants (51 or $42.9 \%$ ) said they kept excess mixed pesticides for the next round of spray. A few participants (5 or $4.2 \%$ ) buried excess mixed pesticides in the ground, or gave it to a neighbour (8 or 6.7\%) (Figure 9). There was a significant difference $\left(\chi^{2}=97.5\right.$, d.f. $\left.=3, p<0.00001\right)$ between response categories in percentages of household replies about excess mixed pesticides. 


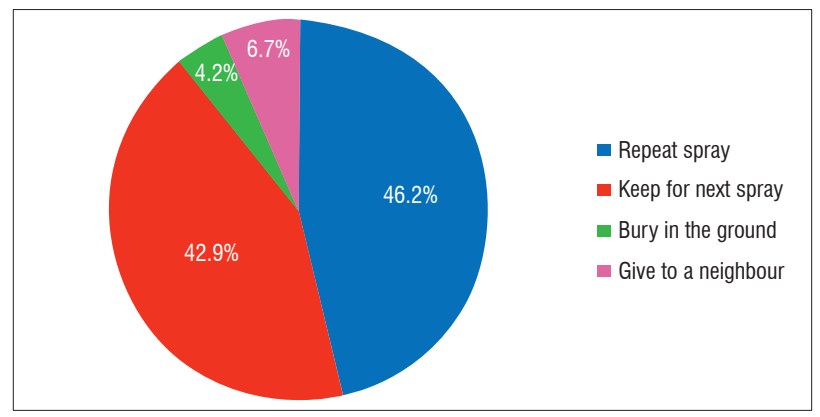

Figure 9: Responses regarding disposal of excess mixed pesticides.

Almost half of the farmers (54 or $45.4 \%$ ) stated that they destroy all empty pesticide containers; a fifth (24 or $20.2 \%$ ) clean all reusable empty containers and use them for domestic purposes; and slightly more than a third (41 or $34.5 \%$ ) keep empty containers for pesticide mixing only (Figure 10). There was a significant difference $\left(\chi^{2}=17.1\right.$, d.f. $=2, p<0.00001$ ) between response categories in percentages of household replies about disposal of empty pesticide containers.

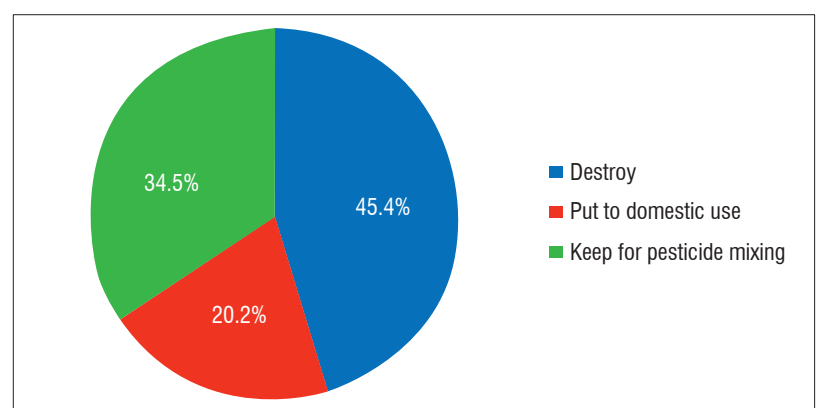

Figure 10: Responses regarding disposal of empty pesticide containers.

Safe disposal of pesticide waste, including used containers, is an important aspect of pesticide management to minimise risk to human health and the environment. ${ }^{1}$ The vast majority of farmers in our study $(89.1 \%)$ either said they continue spraying until all mixed pesticide is used or that they store it for the next round. Safe disposal of empty pesticide containers should be a policy of the ministry of health. ${ }^{1}$ Our survey indicated that $20.2 \%$ of farmers convert to domestic use all usable empty containers after washing. Such use of pesticide containers for household purposes is hazardous, but it is common practice in many countries in the region. ${ }^{18,19}$

\section{Recommendations}

Our study has identified gaps in pesticide management practices among the rural market-gardening community on the outskirts of Harare. These gaps can be addressed only through education and training. There is a need for government agricultural extension workers to organise more outreach training programmes. We also recommend a survey to identify pesticide manufacturers and distributors, and the guidance they give to their rural farming clients in pesticide management. The training programme could take a multidisciplinary approach involving technical inputs and personnel from Ministries of Agriculture and the identified pesticide manufacturers and suppliers. The existing rural farmer training programme offered by agricultural extension officers could be reviewed to align it with current trends.

\section{Authors' contributions}

M.Z. initiated the study, conducted the survey, analysed the data and drafted the manuscript. C.Z. made conceptual contributions, conducted the survey and reviewed the draft manuscript.

\section{Acknowledgements}

We wish to thank Chinamhora and Chihota District Councils for permission to conduct the study.

\section{References}

1. Food and Agriculture Organization of the United Nations. International code of conduct on the distribution and use of pesticides [document on the Internet]. Rome: FA0; 2003 [cited 2015 March 10]. Available from: http://www.fao.org/ docrep/005/y4544e/y4544e00.htm

2. World Health Organization. Public health pesticide registration and management practices by WHO member states [article on the Internet]. Geneva: WHO; 2011 [cited 2015 March 10]. Available from: http://www. whqlibdoc.who.int/publications/2011/9789241501217_eng.pdf

3. World Health Organization. Guidelines on public health pesticide management policy [document on the Internet]. Geneva: WHO; 2010 [cited 2015 March 15]. Available from: http://www.who.int/whopes/resources

4. Mudimu D, Chigume S, Chikanda M. Pestcide use and policy in Zimbabwe: A publication of the Pesticide Policy Project. Hannover: Uni Druck Publishers; Publication Series No 2; 1995. 47 pages.

5. World Health Organization. Global insecticide use for vector-borne disease control [document on the Internet]. Geneva: WH0; 2011 [cited 2015 March 21]. Available from: http://whqlibdoc.who.int/publications/2011/9789241502153_eng.pdf

6. Dong $X$, Simon MA. The epidemiology of organophosphate poisoning in urban Zimbabwe from 1995 to 2000. Int J Occup \& Environ Health 2001;7(4):333-338. http://dx.doi.org/10.1179/oeh.2001.7.4.333

7. Green MA, Heumann MA, Wehr HM, Foster LR, Williams LP Jr, Polder JA et al. An outbreak of watermelon-borne pesticide toxicity. Am J Pub Health. 1987;77:1431-1434. http://dx.doi.org/10.2105/AJPH.77.11.1431

8. Rowley DL, Rab MA, Hardjotanojo W, Liddle J, Burse VW, Saleem M, et al. Convulsions caused by endrin poisoning in Pakistan. Pediatrics. 1987;79:928-934.

9. Tagwireyi D, Ball DE, Nhachi CF. Poisoning in Zimbabwe: A survey of eight major referral hospitals. J Appl Toxicol. 2002;22(2):99-105. http://dx.doi. org/10.1002/jat.832

10. Tagwireyi D, Ball DE, Nhachi CF. Toxicoepidemiology in Zimbabwe: Pesticide poisoning admissions to major hospitals. Clin Toxicol (Phila). 2006;44(1):59 66. http://dx.doi.org/10.1080/15563650500394878

11. Chavez CT, Hepler RS, Straatsma BR. Methyl bromide optic atrophy Am J Ophthalmol. 1985;99:715-719. http://dx.doi.org/10.1016/S00029394(14)76043-X

12. World Health Organization. Public health impact of pesticides used in agriculture [document on the Internet]. Geneva: WHO; 1990 [cited 2015 March 05]. Available from: http://www.who.int/iris/handle/10665/39772

13. Loewenson R, Nhachi CFB. Epidemiology of the health impact of pesticide use in Zimbabwe. In: Nhachi CFB, Kasilo OMJ, editors. Pesticides in Zimbabwe: Toxicity and health implications. Harare: University of Zimbabwe Publications; 1996. p. 25-35.

14. Food and Agriculture Organization / World Health Organization. Amount of poorquality pesticides sold in developing countries alarmingly high [article on the Internet]. Rome: FAO/WHO; 2001 [cited 2015 March 12]. Available from: http:// www.fao.org/WAICENT/OIS/PRESS_NE/PRESSENG/2001/pren0105.htm

15. Magauzi R, Mabaera B, Rusakaniko S, Chimusoro A, Ndlovu N, Tshimanga $M$, et al. Health effects of agrochemicals among farm workers in commercial farms of Kwekwe district, Zimbabwe. Pan Afr Med J. 2011;9:26. http://dx.doi. org/10.4314/pamj.v9i1.71201

16. Issa FO, Atala TK, Akpoko JG, Sanni SA. Adoption of recommended agrochemical practices among crop farmers in Kaduna and Ondo States, Nigeria. Journal of Agricultural Extension. 2015:19(1). 13 pages

17. Ngowi AVF, Mbise TJ, ljani ASM, London L, Ajayi OC. Pesticides use by smallholder farmers in vegetable production in Northern Tanzania. Crop Prot. 2007;26(11):1617-1624. http://dx.doi.org/10.1016/j.cropro.2007.01.008

18. Food and Agriculture Organization / World Health Organization. Guidelines on management options for empty pesticide containers [article on the Internet]. Geneva: FAO/WHO; 2008 [cited 2015 March 25]. Available from: http://www. fao.org/fileadmin/templates/agphome/documents/.Pesticides/../Containers08.p

19. WHO. Safer access to pesticides: Community interventions [document on the Internet]. Geneva: WHO; 2006 [cited 2015 March 12.] Available from: http:// www.who.int/mental_health/prevention/suicide/pesticides_safer_access.pdf 